\title{
Letter from the Editor-in-Chief, 2017
}

\author{
Lawrence J. Berliner ${ }^{1}$
}

Published online: 15 February 2017

(C) Springer Science+Business Media New York 2017

We are pleased to be starting a second year processing excellent work that falls within the scope of Cell Biochemistry and Biophysics. I am particularly grateful to the reviewers, without whom we could not evaluate top-rate science. The names of those reviewers who participated in the 2015-2016 cycles are printed in this issue as recognition of their valuable service. In addition, we could not function without the dedicated assistance of our esteemed Editorial Board. As always, our goal is to accept only high quality papers that fit the aims of our Journal, providing highly significant, high impact communications to the scientific community.

This year, 2017, will see upcoming special issues on current topics of interest in our field, one of which is scheduled for the next issue. We hope to continue these over the years in bringing the work of top-notch international scientists focusing on a contemporary field of importance to our readers.

I encourage you to read our Aims and Scope and Author Instructions on the website and consider submitting to Cell Biochemistry and Biophysics (CBBI).

Lawrence J. Berliner

berliner@du.edu

1 University of Denver, Denver, CO, USA 